\title{
Pathophysiological aspects of the pancreas function in rats with monosodium glutamate-induced obesity
}

\author{
IVAN LESCHENKO ${ }^{1}$, VICTOR SHEVCHUK ${ }^{1}$, OLEKSANDR SAVCHENIUK ${ }^{2}$, \\ TETYANA FALALYEYEVA ${ }^{2}$, TETYANA BEREGOVA ${ }^{2 *}$
}

${ }^{1}$ Bogomolets National Medical University, Ukraine

${ }^{2}$ Taras Shevchenko National University of Kyiv, Ukraine

\begin{abstract}
ABSTRACT: Our study demonstrates that neonatal treatment with monosodium glutamate (MSG) leads to the development of visceral obesity in adult rats. In rats' pancreas of both sexes massive edema and inflammation were found, which are characteristic of acute pancreatitis. Marked intralobular and perivascular lipomatosis was also found. There was also marked leukocyte infiltration in rats with MSG-induced obesity. Morphometric analysis confirmed pathological changes in pancreatic tissue. The level of blood amylase, lipase and pancreatic amylase was increased by $92 \%(\mathrm{p}<0.001), 312 \%(\mathrm{p}<0.001)$ and $162 \%$ ( $\mathrm{p}<0.001)$. So, neonatal treatment with MSG leads to the development of pancreatitis in adulthood of rats. We concluded that the development of pancreatitis in rats with MSG-induced obesity is the result of increase of synthetic and secretory processes in pancreatic cells.
\end{abstract}

Keywords: monosodium glutamate, pancreas, pancreatitis

\section{INTRODUCTION}

Obesity is a problem of the most developed countries. Acute pancreatitis is an initially localized inflammation of the pancreatic gland that frequently leads to local and systemic complications. The incidence of acute pancreatitis in the European Union and USA varies from 5 to 30 cases/ 100 000/year [3]. The overall mortality in patients with acute pancreatitis is around $5 \%$, but this percentage increases up to $17-20 \%$ in patients with necrotic pancreatitis due to multiple organ failure despite the therapeutic efforts to establish it so far [11]. Today in Ukraine 40-50\% of adults and $10-15 \%$ of the child population have problems with the digestive tract and overweight. Obesity and accompanying metabolic disorders are one of the etiologic factors of pancreatic diseases [12]. The last 30 years have been marked by more than two-fold increase in the frequency of pancreatitis, which is certainly due to the low level of physical activity, growth in high-calorie foods diet and uncontrolled use of food additives, especially monosodium glutamate (MSG).

\footnotetext{
Corresponding author

* Department of Pharmaco-Physiology,

Taras Shevchenko National University of Kyiv,

Volodymyrska Str., 64/13, Kyiv, 01601, Ukraine

e-mail: tberegova@mail.ru
}

A food additive MSG is used as a flavoring agent to enhance taste. Although the evaluations conducted by the U.S. Food and Drug Administration and some other organizations confirmed that MSG was a safe food ingredient for the general population, none of them answered the question if consumption of MSG is healthy [5]. Understanding the influence of MSG on the pancreas may lead to a new understanding of the pathophysiology of diseases such as diabetes, pancreatitis. Therefore, the aim of this work was to study the morphological changes in the pancreatic tissue and exocrine pancreatic function of rats under experimental obesity caused by MSG.

\section{MATERIAL AND METHODS}

The study was carried out on 60 white rats maintained in accordance with guidelines of Animal Ethical Research Committee of Taras Shevchenko National University of Kyiv. The animals were deprived of food for $24 \mathrm{hr}$ period to the experiments with an easy approach to water. The rats were divided into 3 groups. Rats of group I were intact control (4-month-old rats). Newborn rats of groups II and III were administered subcutaneously in volume $8 \mu \mathrm{l} / \mathrm{g}$ a placebo (saline) or MSG $(4 \mathrm{mg} / \mathrm{g})$ on $2^{\text {nd }}, 4^{\text {th }}, 6^{\text {th }}, 8^{\text {th }}, 10^{\text {th }}$ day of life. After 4 months we performed histological and morphometric study of pancreatic tissue of all rats. We

DOI: 10.12923/j.2084-980X/26.4/a.01 
used lethal dose of urethane ( $3 \mathrm{~g} / \mathrm{kg}$, intraperitoneally) for rats sacrifice. Pancreas' tissue sections waere fixed in $10 \%$ formalin, embedded in paraffin, stained with hematoxylin and eosin. On micrographs obtained with increasing $\mathrm{x}$ 150-900 we delineated the cross section of nuclei of endocrine and exocrine pancreatic cells, cross section of exocrine pancreatic cells and distance between lobules of the pancreas. Then we calculated their area using the open source software UTHSCSA ImageTool that was developed in Texas state university, San Antonio, Texas in 1995-2002 years and accessible on the Internet at $\mathrm{ftp}: / / \max$ rad6.uthscsa.edu.

In addition, changes in body and visceral fat weight were analyzed. Serum amylase and lipase level was determined by biochemical analysis. The concentration of adiponectin and triglycerides in blood serum of all groups was performed by ELISA analysis (Assay Pro, USA).

According to Shapiro-Wilks' W test our data were normally distributed. All results are expressed as the $\mathrm{M} \pm \mathrm{m}$ of $\mathrm{n}$ values. Statistical comparisons between groups were conducted using the Student's t-test for unpaired data. Statistical significance was set at $\mathrm{p} \leq 0.05$.

\section{RESULTS}

It has been shown that pancreatic tissue in rats of groups I and II have normal structure. Significant changes in body weight and visceral fat were not observed in these groups. In control and placebo groups, the triglyceride levels (TG) were in normal range. In male rats, there were more pronounced changes - body weight and visceral fat exceeded benchmarks in 3 -fold $(p \leq 0.001)$ and 5-fold $(\mathrm{p} \leq 0.001)$ respectively. Body weight and visceral fat of female rats in group III was higher by $125 \%(\mathrm{p} \leq 0.001)$ and $338 \%(p \leq 0.001)$, respectively. The adiponectin levels in serum decreased in male rats by $59 \%(\mathrm{p} \leq 0.05)$ and in female rats by $23 \%(\mathrm{p} \leq 0.05)$ compared with intact rats. In our study, we have diagnosed moderate hypertriglyceridemia (HTG) (TG - 2.3-11.2 mmol/L) in all rats with MSG-induced obesity.

In pancreas of rats of both sexes there was massive edema and inflammation which are characteristic of acute pancreatitis. Marked intralobular and perivascular lipomatosis was found. There was also marked leukocyte infiltration in the pancreatitis groups. The level of blood amylase, lipase and pancreatic amylase was increased by $92 \%(p<0.001), 312 \%(p<0.001)$ and $162 \%(p<0.001)$ (Fig. 1). Morphometric analysis confirmed pathological changes in pancreatic tissue. The cross-sectional area of nuclei of endocrine cells was increased in males by $16 \%$ $(p<0.001)$ and in females by $17 \% \quad(p<0.001)$. The cross-sectional area of nuclei of exocrine pancreatic cells was increased in males by $15 \%(\mathrm{p}<0.001)$ and in females $12 \%(p<0.001)$. Cross-sectional area of Langerhans islet was increased in males by $50 \%(\mathrm{p}<0.05)$ and in females by $48 \%(p<0.05)$. The distance between lobules of the pancreas was increased in males by $63 \%(p<0.001)$ and in females by $56 \%(p<0.001)$ but the cross-sectional area of the exocrine pancreatic cells was decreased in males by $16 \%(\mathrm{p}<0.001)$ and in females by $17 \%(\mathrm{p}<0.001)$ (Table 1$)$.

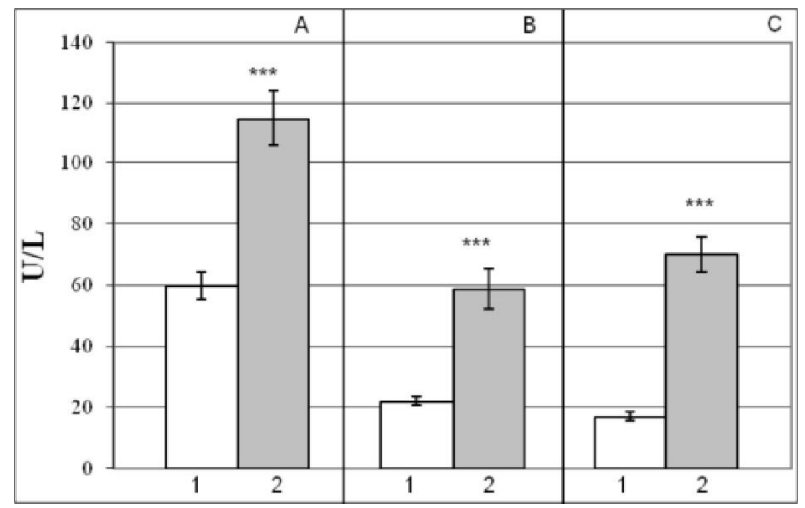

Fig. 1. The serum blood concentration of amylase (A), pancreatic amylase (B) and lipase (C) in rats with monosodium glutamateinduced obesity: 1 - control; 2 - monosodium glutamate-induced obesity

\section{DISCUSSION}

Our study demonstrates that neonatal treatment with MSG leads to the development of visceral obesity in adult rats. Furthermore, the present data confirm previous results showing that neonatal treatment with MSG may induce obesity [10]. Neonatal MSG treatment is a model

Table 1. Morphometric characteristic of rats' pancreas

\begin{tabular}{|c|c|c|c|c|}
\hline \multirow[b]{2}{*}{ Indicators } & \multicolumn{2}{|c|}{ Male } & \multicolumn{2}{|c|}{ Female } \\
\hline & $\begin{array}{c}\text { Control } \\
\mathrm{n}=10\end{array}$ & $\begin{array}{l}\text { Glutamate } \\
\mathrm{n}=10\end{array}$ & $\begin{array}{c}\text { Control } \\
\mathrm{n}=10\end{array}$ & $\begin{array}{l}\text { Glutamate } \\
\mathrm{n}=10\end{array}$ \\
\hline $\begin{array}{l}\text { Cross-sectional area of nuclei of endocrine cells } \\
\left(\mu \mathrm{m}^{2}\right)\end{array}$ & $\begin{array}{l}20.6 \pm 0.3 \\
(N=100)\end{array}$ & $\begin{array}{l}23.9 \pm 0.6 * * * \\
(\mathrm{~N}=100)\end{array}$ & $\begin{array}{l}20.5 \pm 0.3 \\
(N=100)\end{array}$ & $\begin{array}{l}23.4 \pm 0.5^{* * *} \\
(\mathrm{~N}=100)\end{array}$ \\
\hline $\begin{array}{l}\text { Cross-sectional area of nuclei of exocrine pancreatic } \\
\text { cells }\left(\mu \mathrm{m}^{2}\right)\end{array}$ & $\begin{array}{l}19.8 \pm 0.3 \\
(\mathrm{~N}=100)\end{array}$ & $\begin{array}{l}22.8 \pm 0.4^{* * *} \\
(\mathrm{~N}=100)\end{array}$ & $\begin{array}{l}19.8 \pm 0.3 \\
(N=100)\end{array}$ & $\begin{array}{l}22.2 \pm 0.4 * * * \\
(\mathrm{~N}=100)\end{array}$ \\
\hline $\begin{array}{l}\text { Cross-sectional area of the exocrine pancreatic cells } \\
\left(\mu \mathrm{m}^{2}\right)\end{array}$ & $\begin{array}{c}1273.0 \pm 62.7 \\
(N=100)\end{array}$ & $\begin{array}{l}1069.5 \pm 45.0 * * * \\
(\mathrm{~N}=100)\end{array}$ & $\begin{array}{c}1296.0 \pm 50.0 \\
(N=100)\end{array}$ & $\begin{array}{l}1076.0 \pm 37.0 * * * \\
(\mathrm{~N}=100)\end{array}$ \\
\hline $\begin{array}{l}\text { The distance between lobules of the pancreas } \\
(\mu \mathrm{m})\end{array}$ & $\begin{array}{l}2.7 \pm 0.1 \\
(\mathrm{~N}=100)\end{array}$ & $\begin{array}{c}4.4 \pm 0.2 * * * \\
(\mathrm{~N}=100)\end{array}$ & $\begin{array}{l}2.56 \pm 0.1 \\
(\mathrm{~N}=100)\end{array}$ & $\begin{array}{c}4.0 \pm 0.2 * * * \\
(\mathrm{~N}=100)\end{array}$ \\
\hline Cross-sectional area of Langerhans islet & $\begin{array}{l}11790.0 \pm 2236.5 \\
(N=100)\end{array}$ & $\begin{array}{c}17633.0+2442^{*} \\
(N=100)\end{array}$ & $\begin{array}{l}11690.0 \pm 2043.0 \\
(N=100)\end{array}$ & $\begin{array}{l}17360.0+1815.0 * \\
(N=100)\end{array}$ \\
\hline
\end{tabular}

$\mathrm{M}+\mathrm{m},{ }^{*} \mathrm{p}<0.05,{ }^{* * *} \mathrm{p}<0.001$ compared with control, $\mathrm{n}$ - number of animals, $\mathrm{N}$ - number of measurements. 
of obesity in rodents, which causes alterations in hypothalamic arcuate nucleus (ARC) and impairs leptin and insulin signaling in this region resulting in hyperleptinemia and hyperinsulinemia. When the hypothalamic ventromedial nucleus and arcuate nucleus are destroyed in rats by treatment with MSG in the neonatal stage, obesity occurs as the rats grow [9].

Obesity is a prognostic factor for severity in the evolution of acute pancreatitis since local and systemic complications are more frequent in obese patients than in non-obese ones. Hypertriglyceridemia (HTG), depending on its severity, can lead to development of acute or chronic pancreatitis, pancreatic insufficiency, pancreatic necrosis, pancreatic abscess or pancreatic pseudocyst [2]. Patients with the history of chylomicronemia in family have increased lifelong risk of recurrent pancreatitis. This risk increases with observed severe HTG (TG $11.2 \mathrm{mmol} / \mathrm{L}$ ) and is greatest due to very severe HTG (TG22.4 mmol/L) [13]. Pancreatitis due to HTG can be serious and sometimes fatal. HTG-induced pancreatitis is related to increased activity of exocrine pancreatic lipase, which ectopically mediates hydrolysis of circulating TG. The partially hydrolyzed fatty acids are thought to be injurious to acinar cells, leading to activation of trypsinogen and local autodigestion of pancreatic tissue. Increased chylomicrons might further worsen the process by causing capillary plugging and local ischemia [8].

In our study, we diagnosed moderate HTG (TG $2.3-11.2 \mathrm{mmol} / \mathrm{L}$ ) in all rats with MSG-induced obesity. In control and placebo groups, the levels of TG were in normal range. Also only in rats with obesity we found intralobular and perivascular lipomatosis of pancreas with hyperamylasemia. Frulloni et al. (2006) in human studies found that HTG can lead to pancreatic steatosis diagnosed by Magnetic Resonance Imaging (MRI) with serum pancreatic hyperenzymemia, which is higher than in normal controls. But unlike our study, the author found intraacinar accumulation of lipids (similarly to hepatic steatosis) which may alter intracellular exocytosis [6]. Another study postulated that hyperenzynemia is not specific to pancreatic steatosis [7]. The use of MRI in patients with dyslipidemia, does not show any signs of it. Furthermore, patients with severe acute pancreatitis exhibit higher percentage of fat than those with mild acute pancreatitis [15]. In addition, obese Zucker rats exhibited TNF-á expression and higher mortality rate than controls in the experimental model of acute pancreatitis induced by taurocholate [14].

It has been established that the serum adiponectin level decreases in rats with MSG-induced obesity. A decrease in adiponectin level is a feature of obese animals and it might contribute to the severity of pancreatitis since adiponectin exhibits anti-inflammatory properties and a deficiency in adiponectin causes severe pancreatitis in mice with a high-fat diet, whereas its over-expression pro- tects against tissue damage [1]. Adipose tissue and particularly the areas of fat necrosis are important sources of inflammatory mediators that may contribute to the systemic inflammatory response in acute pancreatitis [4]. Nevertheless, the mechanisms responsible for the increased severity of acute pancreatitis in obese subjects are still under investigation.

This study proved that in rats' pancreas massive edema and inflammation developed, which are characteristic for acute pancreatitis. We also reported that plasma amylase, lipase and pancreatic amylase increased levels are much higher in obese rats than in control rats. We arrived at the conclusion that the development of pancreatitis in rats with MSG-induced obesity is the result of increase of synthetic and secretory processes in pancreatic cells. Thus, we can include glutamate to the group of substances stimulating pancreatic secretion.

\section{CONCLUSIONS}

1) Neonatal treatment with MSG leads to massive edema, inflammation, intralobular and perivascular lipomatosis of pancreas in adult rats, with the development of exocrine pancreatic secretion.

2) Visceral obesity, moderate hypertriglyceridemia and low serum adiponectin may be causes of pathological changes in pancreas.

\section{REFERENCES}

1. Araki $\mathrm{H}$. et al.: Adiponectin plays a protective role in caerulein-induced acute pancreatitis in mice fed a high-fat diet. Gut, 57, 1431-1440, 2008.

2. Brahm A., Hegele R.: Hypertriglyceridemia. Nutrients, 5, 981-1001, 2013.

3. Ellis M.P., French J.J., Charnley R.M. Acute pancreatitis and the influence of socioeconomic deprivation. Br. J. Surg., 96, 74-80, 2009.

4. Franco-Pons N., Gea-Sorlí S., Closa D. Release of inflammatory mediators by adipose tissue during acute pancreatitis. J. Pathol., 221, 175-182, 2010.

5. Freeman M.: Reconsidering the effects of monosodium glutamate: a literature review. J. Am. Acad. Nurse Pract., 18, 10, 482-486, 2006.

6. Frulloni L. et al.: Pancreatic hyperenzymemia: clinical significance and diagnostic approach. JOP. J. Pancreas (Online), 6, 536-51, 2006.

7. Gullo L. Benign pancreatic hyperenzymemia or Gullo's syndrome. JOP., 7, 241-242, 2007.

8. Khokhar A.S., Seidner D.L.: The pathophysiology of pancreatitis. Nutr. Clin. Pract., 19, 5-15, 2004.

9. Nakagawa T. et al.:Effects of chronic administration of sibutramine on body weight, food intake and motor activity in neonatally monosodium glutamate-treated obese female rats: relationship of antiobesity effect with monoamines. Exp. Anim., 49, 239-249, 2000.

10. Oida K. et al.: Plasma lipoproteins of monosodium glutamate-induced obese rats. Int. J. Obes., 8, 5, 385-391, 1984.

11. Pandol S.J. et al.: Acute pancreatitis: bench to the bedside. Gastroenterology, 133, 1056, 1-25, 2007. 
12. Pereda J. et al.: Obese rats exhibit high levels of fat necrosis and isoprostanes in taurocholate-induced acute pancreatitis. PLoS ONE, 7, 9, 44383, 2012.

13. Sandhu S. et al.: Incidence of pancreatitis, secondary causes, and treatment of patients referred to a specialty lipid clinic with severe hypertriglyceridemia: A retrospective cohort study. Lipids Health Dis., 10, 157, 2011.
14. Segersvärd R. et al.: Obesity alters cytokine gene expression and promotes liver injury in rats with acute pancreatitis. Obesity, 16, 23-28, 2008.

15. Sempere L. et al.: Obesity and fat distribution imply a greater systemic inflammatory response and a worse prognosis in acute pancreatitis. Pancreatology, 8, 257-264, 2008. 